\title{
Vertical Integration and Market Power in Electricity Markets
}

\author{
Seamus Hogan ${ }^{\dagger}$ \\ Senior Lecturer \\ Department of Economics \\ University of Canterbury \\ Email:seamus.hogan@canterbury.ac.nz
}

Richard Meade

New Zealand Institute for the Study of Competition and Regulation

Victoria Management School

Cognitus Advisory Services Limited

Email: richard.meade@cognitus.co.nz

18 February 2007

\begin{abstract}
:
Vertical separation of generation from electricity retailing has often been required as a condition of electricity market liberalisation. A well-developed and liquid contracts market is similarly suggested as necessary to manage the resulting wholesale market risks, which risks are further exacerbated by competition. Such contracts markets are rare, however, and increasingly evidence is emerging that vertical integration is associated not just with improved wholesale market risk management, but also reduced wholesale market power. This paper develops a theoretical model showing that non-vertically integrated generators will over-report their inverse supply curves, with the incentive to over-report increasing with the firm's share of generating capacity. Conversely, in a vertically integrated industry, no over-reporting occurs when integrated firms have balanced shares in wholesale and retail markets. In general, firms whose share of generating capacity is higher (lower) than their retail market share will over-report (under-report) their inverse supply functions. Integration is found to affect retail electricity prices only via its effect on retail marginal costs. We find that retail prices are higher with vertical separation than with either balanced integration, or full integration without a wholesale market. These results suggest a re-evaluation of the importance of generator wholesale market power in vertically integrated electricity industries, and of measures to improve retail market competitiveness under either vertical integration or separation.
\end{abstract}

${ }^{\dagger}$ Corresponding author. 


\section{Introduction}

Conventional wisdom in electricity restructuring requires electricity generation to be horizontally separated, as well as de-integrated from open-access transmission, to enable competition between generators in wholesale electricity markets (Newbery (2002)). Moreover, the separation of electricity distribution from retailing is sometimes suggested to prevent possible use of market power in distribution to foreclose retail competition (Riechmann (2000)). However, despite empirical evidence from other industries indicating that vertical integration is apparently beneficial to consumers (e.g., Cooper et al. (2005)), consensus is less settled on whether generation should be vertically integrated with, or separated from, electricity retailing. While significant steps towards vertical unbundling have been taken at various stages in systems such as California, New England, Norway and Italy, this has not been the case in others such as PJM, ${ }^{1}$ much of Europe (e.g. Spain, France) and New Zealand.

With vertical integration, contracts markets become thin and any non-integrated retailers are exposed to potentially ruinous wholesale price volatility. This failure risk deters entry in retailing and thereby potentially reduces retail market competition. At the same time, however, integration can also reduce the incentive for generators to exercise market power in wholesale markets (Mansur (2004)). With vertical separation - given that electricity contracts markets are typically thin or even unavailable (Newbery (2002), Chao et al. (2005)) - all retailers face potentially extreme wholesale price risk. ${ }^{2}$ Conversely, greater integration reduces generator-retailers' reliance on contracts markets to manage their wholesale price exposure, both reducing bankruptcy risks and improving investment economics (Buehler et al. (2003), Finon (2006)). While integration may increase retail market power, this may not be entirely detrimental, preserving or even enhancing generation investment incentives (Dupuy (2006)), especially where wholesale price caps have been imposed (whether to combat perceived generator market power, or simply to limit wholesale price peaks).

Despite these debates, evidence is emerging from restructured electricity markets that vertical integration can provide an important substitute for inadequate contract markets, and significantly influence market performance. Bushnell et al. (2004) compare market performance in the three largest and oldest US electricity markets - California, PJM and New England. They find that similar horizontal structures can produce dramatically different outcomes under different vertical arrangements. Whereas California had less concentration and greater import capacity than the other two, its complete lack of vertical integration and long-term contracting contributed to it experiencing higher electricity prices. Similarly, Borenstein et al. (2002) and Joskow and Kahn (2002) document evidence of market power being exercised in California, which contrasts with evidence from Bushnell and Saravia

1 The PJM Interconnection is the world's largest competitive wholesale electricity market. It coordinates the movement of wholesale electricity in all or parts of Delaware, Illinois, Indiana, Kentucky, Maryland, Michigan, New Jersey, North Carolina, Ohio, Pennsylvania, Tennessee, Virginia, West Virginia and the District of Columbia.

2 See Borenstein (2002), Wilson (2002) and Mansur (2003) regarding California's experience in particular. 
(2002) of only modest market power being exercised in New England (where vertical separation was also enforced, but with vesting contracts).

In this paper we concentrate on the effects of vertical integration between generation and retailing on the exercise of both wholesale and retail market power. We model spot wholesale and retail electricity markets assuming that a fixed number of generators compete to sell into the wholesale market via a sealed-bid auction. We proceed using a two-stage game in which retail prices are first set for committed supply, and then generators make their wholesale bids subject to a price-inelastic total demand. Of particular interest is the incentive for generators to overstate their inverse supply curves, in turn reflecting the extent to which they can influence the single wholesale clearing price. This incentive is examined in the cases of vertical separation and integration, and then extended to also consider retail prices. We find that generators always overstate prices when vertically separated from retailing, with the incentive to overstate inversely related to generator market share. Conversely, when generators are vertically integrated with the same retail market share as their respective wholesale market share, a Nash equilibrium exists with no over-reporting of inverse supply curves. More generally, firms with higher (lower) wholesale market share than retail market share will over-report (under-report). Finally, retail prices are higher in a market with vertical separation than in one with either full integration and no wholesale market, or with vertical integration and each firm having inter-market balance.

The paper is organised as follows. To report an unusual natural experiment resulting in the formation of a vertically integrated electricity sector, Section 2 briefly describes the New Zealand electricity market, and summarises its unusual path to vertical integration. Section 3 sets out the market structure assumed in our model. Section 4 analyses generators' pricing incentives in our assumed wholesale market structure assuming at first that there is no vertical integration. Section 5 then allows for vertical integration. Section 6 extends the analysis to the retail market. Implications of our results are then discussed in Section 7. Finally, section 8 concludes.

\section{The New Zealand Electricity Market and its Path to Vertical Integration}

As discussed in Evans and Meade (2005), the New Zealand electricity system comprises two main subsystems, based in the country's North and South Islands, interconnected via an HVDC link. The system is predominantly hydro-based $(60.5 \%$ of the total $8,840 \mathrm{MW}$ capacity), of which 65\% is located in the South Island (MED (2006)). This typically necessitates export of power north through the HVDC link, to demand centres concentrated predominantly in the upper North Island. Lake storage is relatively limited, however, and seasonal hydro inflows are highly volatile, exposing the system to tight supply conditions in "dry" years. Gas- and coal-based generation account for only $30 \%$ of capacity, with the single largest other generation type being geothermal (5\% of capacity).

All electricity is traded through a "gross pool" wholesale electricity market, despite around $15 \%$ of annual energy demand being supplied under long-term contract to an aluminium smelter (New Zealand Aluminium Smelter, NZAS). Prices are set on a half-hourly basis at 244 nodes throughout the country, with price separation between nodes reflecting transmission constraints and losses. Generation is dispatched on a least-cost basis by the grid 
owner and operator, Transpower, using an "n-1" security-constrained optimisation model called SPD (Scheduling, Pricing and Dispatch).

Generation is dominated by five companies, accounting for around $91 \%$ of generation capacity and $97 \%$ of total demand. These generators are all vertically integrated into retailing, forming so-called "gentailers". In this respect the New Zealand market compares with that of Spain, in which four firms account for 93\% of generation and $97 \%$ of retail sales (Kuhn and Machado (2004)). According to Evans and Meade (2005), the gentailers have net generation positions ranging from around $-7 \%$ (Contact Energy) to +2\% (Mighty River Power).

New Zealand's current position contrasts with that existing before, and even during much of, the electricity sector restructuring commencing in 1984. At that time $95 \%$ of generation capacity was state-owned, and integrated with transmission. While the then stateowned monopoly, Electricity Corporation of New Zealand (ECNZ), directly supplied a handful of large industrial customers, all electricity retailing had to that point been undertaken by locally- or municipally-owned concerns, which also supplied distribution services.

The evolution of the New Zealand market from initial to present arrangements followed an unexpected course, and one which differed from that in many other reforming jurisdictions. Early reforms focused on the corporatisation of the combined retailing and distribution concerns, and the separation of transmission from ECNZ into the stand-alone state-owned grid company, Transpower. The vertical separation of generation from retailing was unnecessary, given they were not then already combined. Subsequently, the horizontal separation of ECNZ was necessitated to support the development of a competitive wholesale electricity market, the NZEM. This first took the form of a spinout of certain ECNZ generation assets into a separate state-owned enterprise, Contact Energy, which was quickly privatised. Full trading operations on the NZEM were then able to commence in October 1996. ECNZ was finally separated into three more competing state-owned generators in April 1999, Genesis, Meridian and Mighty River Power.

Coinciding with ECNZ's final break-up were two other reforms that radically but unintentionally led to New Zealand's vertically integrated structure. First, with ECNZ's generation dominance now removed, generators were permitted to own retailing activities which ECNZ had previously been deterred from acquiring. Second, controversial legislation requiring ownership separation between retailing and distribution activities, the Electricity Industry Reform Act 1998, also came into force. The acquisition of the retailing arms of almost all of the hitherto distributor-retailers by generators rapidly ensued. This was the intention of neither the separation of ECNZ into competing generators, nor the ownership unbundling of distributor-retailers.

The "gentailer" model took two more years to achieve outright dominance, aided in part by an unusually dry winter in the middle of 2001, resulting in extremely low hydro storage levels. Natural Gas Corporation (NGC) had not long previously acquired the single largest retail customer base in the country, but had little generation capacity of its own. NGC's existing hedge contracts began to expire in early 2001, but the company resisted entering into replacement contracts because it regarded the prices then available as excessive. ${ }^{3}$ With tight

3 See “Mighty River Contracts 'Vindicated' in Wholesale Power Price Crisis,” National Business Review, 24 August 2001. 
supply conditions arising during the months of peak winter demand, the wholesale prices faced by NGC rose significantly, while competition with other (vertically integrated) energy retailers limited its ability to raise retail prices. Facing losses exceeding NZ\$300 million (US\$125 million at then exchange rates) the company was consequently forced in August 2001 to divest its retail customers to generators whose generation capacity provided a natural hedge against high wholesale prices. Wholesale prices fell from their highs to more typical levels soon thereafter, although hydro lake levels did not recover until much later in the year. ${ }^{4}$ Both the April 1999 reforms and the 2001 "dry winter" provided natural experiments illustrating the natural inclination and risk-management rationale for generators to acquire retail customer bases.

The resulting state of affairs has not received wide approval. Dry winters in 2003 and 2006 resulted in episodes of sustained spiking wholesale electricity prices, as in 2001. Such episodes frequently led to accusations of the wholesale electricity market being flawed, of New Zealand's reforms having "failed", and of market power abuse by gentailers. They spurred the government to impose a reserve generation scheme in 2003 to provide a limited amount of additional capacity for use in dry winters. Government also provided a one-off underwrite of gas exploration risks for state-owned Genesis in 2004, to support the development of its proposed gas-fired plant, e3p, and thereby to bolster supply security. The New Zealand Electricity Commission, charged with industry regulation, has been empowered to force generators to issue contracts for some portion of their output to stimulate the development of a contracts market, despite gentailers currently being essentially fully hedged. Finally, in May 2005 New Zealand's competition authority, the Commerce Commission, launched an inquiry into whether the country's five largest generators were abusing market power in the wholesale market. The role of vertical integration in managing wholesale market risks, supporting investment in new generation to enhance supply security, and influencing the exercise of generator market power, currently remain unsettled questions in New Zealand (e.g. see Meade (2005a, b)).

\section{The Market Structure}

We assume that the market for electricity consists of a wholesale and a retail market. In the wholesale market, electricity generators compete for the right to supply electricity and retailer companies compete for the right to buy via a sealed-bid auction. In the retail market, retail companies compete for customers by posting prices. We model this market as a static two-stage game. In the first stage, retailers post prices and agree to supply whatever their customers demand at those prices. In the second stage, generators submit and retailers submit supply and demand bids to a market maker, who sets the price to equate total demand to total supply. In this model with a single market-clearing price, we have assumed away the complications that arise from the spatial separation of generators from end users and the resulting energy loss of transmission that necessitates separate prices at each injection and exit point. We have also assumed away the possibility of system failure that necessitates a reserve market.

4 This contrasts with the 2003 “dry winter” in which spiking wholesale prices fell to more normal levels at around the same time as hydro levels recovered. 
Because of the sequencing of the two markets, retailers are committed to supplying to consumers whatever quantity of electricity is demanded before the wholesale auction takes place; accordingly, we assume that retailers submit inelastic demand bids to the market maker, at least in region where equilibrium prices emerge. Sellers, however, are assumed to submit upward-sloping supply curves. The assumption of inelastic demand bids in the wholesale market is designed to capture the relative stickiness of retail electricity prices due to the different time horizons between the retail and wholesale markets-retail customers typically face monthly billing, whereas the wholesale market is commonly repeated every hour or half hour.

\section{The Wholesale Market with no Vertical Integration}

In this section, we consider a market with a fixed number of generators competing to sell into the wholesale market via a sealed-bid auction. We assume that the total demand in any period is inelastic in the wholesale price. Furthermore, at this stage we assume that the generators have no presence in the retail market and so have no impact on the size of that inelastic demand.

Let the true supply curve for firm $i$ in the wholesale market for electricity be $y_{i}\left(p_{w}\right)$, and let the true market supply curve be $Y\left(p_{w}\right)$. Let each firm's true supply curve be a constant fraction of the market supply curve at each price so that

$$
y_{i}\left(p_{w}\right)=\theta_{i} Y\left(p_{w}\right)
$$

with

$$
\sum_{i} \theta_{i}=1
$$

The assumption that the firms' true supply curves differs from each other only by a scale factor is a simply a mathematical convenience that allows us to express the firm's relative size as a single number, $\theta_{i}$. It is not crucial to the intuition. We will refer to $\theta_{i}$ as firm $i$ 's "natural market share". The natural market share will correspond exactly to the realised market share only to the extent that all firms over-report their supply curves in the same proportion.

Let $p_{i}(y)$ be firm i's inverse supply curve, so that

$$
p_{i}(y)=c_{i}^{\prime}(y),
$$

where $c_{i}(y)$ is firm i's cost function. We assume increasing marginal cost so that the individual supply curves are well defined and increasing.

The wholesale price is determined by having each firm announce a putative supply curve, the sum of which produces an announced market supply curve. The intersection of this announced supply curve with the fixed demand sets the market wholesale price, and firms are then obliged to produce up to that point on their announced supply curves while receiving the market price for each unit.

Let $\hat{p}_{i}(y)$ be firm i's announced inverse supply curve, and let $\lambda_{i}$ be the extent to which firm $i$ overstates its inverse supply curve, so that

$$
\hat{p}_{i}(y)=\lambda_{i} p_{i}(y)=\lambda_{i} c_{i}^{\prime}(y) .
$$


The announced supply curve, $\hat{y}_{i}\left(p_{w}\right)$, is then

$$
\begin{aligned}
\hat{y}_{i}\left(p_{w}\right) & =y_{i}\left(p_{w} / \lambda_{i}\right) \\
& =\theta_{i} Y\left(p_{w} / \lambda_{i}\right) .
\end{aligned}
$$

Let $p_{i}=p_{w} / \lambda_{i}$. The effect of a change in price on firm $i$ 's demand is then

$$
\frac{\partial y_{i}}{\partial p_{w}}=\theta_{i} \frac{\partial Y\left(p_{i}\right)}{\partial \hat{p}_{i}} \cdot \frac{1}{\lambda_{i}} .
$$

To lighten the notation, it will be convenient to define the marginal realised market share of firm $i, \omega_{i}$ :

$$
\omega_{i}=\frac{\frac{\partial y_{i}}{\partial p_{w}}}{\sum_{j} \theta_{j} \frac{\partial y_{j}}{\partial p_{w}}}=\frac{\theta_{i} \frac{\partial Y\left(p_{i}\right)}{\partial p_{i}} \cdot \frac{1}{\lambda_{i}}}{\sum_{j} \theta_{j} \frac{\partial Y\left(p_{j}\right)}{\partial p_{j}} \cdot \frac{1}{\lambda_{j}}}
$$

Note that $\omega_{i} \in[0,1]$ with $\omega_{i}=0$ (resp. 1) as $\theta_{\mathrm{i}}=0$ (resp.1). Let $X$ be the fixed demand for wholesale electricity. The equilibrium wholesale price is then the solution to

$$
\sum_{j} \theta_{j} Y\left(p_{w} / \lambda_{j}\right)=X
$$

From the implicit-function theorem,

$$
\frac{d p_{w}}{d \lambda_{i}}=\frac{\theta_{i} \frac{\partial Y}{\partial p_{i}} \cdot \frac{p_{w}}{\lambda_{i}^{2}}}{\sum_{j} \theta_{j} \frac{\partial Y}{\partial p_{j}} \cdot \frac{1}{\lambda_{j}}}=\frac{p_{w}}{\lambda_{i}} \omega_{i}
$$

The profit of firm $i$ in the wholesale market is

$$
\pi_{w i}=p_{w}\left(\lambda_{i}\right) \cdot y_{i}\left(p_{i}\right)-c\left(y_{i}\left(p_{i}\right)\right)
$$

so

$$
\begin{aligned}
\frac{\partial \pi_{w i}}{\partial \lambda_{i}} & =\frac{\partial p_{w}}{\partial \lambda_{i}} y_{i}+\left(p_{w}-c^{\prime}\left(y_{i}\right)\right) \frac{\partial y_{i}}{\partial \hat{p}_{i}} \cdot \frac{\partial p_{i}}{\partial \lambda_{i}} \\
& =\frac{\partial p_{w}}{\partial \lambda_{i}} y_{i}+p_{w}\left(\frac{\lambda_{i}-1}{\lambda_{i}}\right) \cdot \frac{\partial y_{i}}{\partial p_{i}} \cdot \frac{\partial p_{i}}{\partial \lambda_{i}} \\
& =\theta_{i} \frac{\partial p_{w}}{\partial \lambda_{i}} Y\left(p_{i}\right)+\theta_{i} \frac{p_{w}}{\lambda_{i}^{2}} \cdot\left(\frac{\lambda_{i}-1}{\lambda_{i}}\right) \cdot \frac{\partial Y\left(p_{i}\right)}{\partial p_{i}} \cdot\left(\lambda_{i} \frac{\partial p_{w}}{\partial \lambda_{i}}-p_{w}\right) \\
& =\theta_{i} \frac{p_{w}}{\lambda_{i}}\left(Y\left(p_{i}\right) \omega_{i}+\frac{\partial Y\left(p_{i}\right)}{\partial p_{i}} \cdot \frac{p_{w}}{\lambda_{i}} \cdot\left(\frac{\lambda_{i}-1}{\lambda_{i}}\right)\left(\omega_{i}-1\right)\right)=0
\end{aligned}
$$

From this first-order condition, we can derive the following result: 


\section{Theorem 1:}

In any Nash equilibrium with $\alpha_{i} \in(0,1) \forall i$, all firms will over-report their supply curves, with over-reporting tending to increase as natural market share increases.

\section{Proof:}

From Equation (1), we have $\partial \pi_{w i} / \partial \lambda_{i}>0$ if $\lambda_{i} \leq 1$, implying that not over-reporting is always a dominated strategy. If we treat $\omega_{i}$ as a parameter that is independent of the $\lambda_{j}$, it is clear that $\partial \lambda_{i} / \partial \omega_{i}>0$. While, $\omega_{i}$ is not necessarily monotone increasing in $\theta_{i}$, the increasing relationship between $\omega_{i}$ and $\lambda_{j}$ make it clear that in the limit, as $\theta_{i} \rightarrow 0, \lambda_{i} \rightarrow 1$, and that as $\theta_{i} \rightarrow 1, \lambda_{i} \rightarrow \infty$.

Theorem 1 is essentially a Cournot result. That is, it shows that the Nash outcome of the kind of sealed-bid auction modelled here has over-reporting but with market power decreasing as market share decreases (say, through an increase in the number of firms), with perfect competition emerging in the limiting case of atomistic firms.

\section{The Wholesale Market with Vertical Integration}

Now consider the retail market for electricity. Retail firms buy their electricity from the wholesale market at price, $p_{w}$, and sell it at a firm-specific price. In addition to the wholesale cost, there is an additional cost of $c_{r i}\left(x_{i}\right)$ to firm $i$ from selling $x_{i}$ units of retail electricity. This includes fixed and marginal costs of transmission and operating in the retail market. We assume that this cost is independent of the wholesale price, so, for example, transmission costs are not priced as a mark-up on the wholesale price.

We consider the pricing decision of retail firms, which constitutes the first stage of the two-stage game, in the next section. In this section, we consider the effect of vertical integration between generators and retailers on the second-stage game that is the wholesale market. This means, we take the firms' retail prices as given at the time the auction strategies are being determined. The only change that vertical integration has on the model from the previous section, then, is that each wholesale firm will also have some proportion of the fixed demand, $X$, that will be their own demand as a retailer. Let $\beta_{i}$ be generation firm i's share of total demand in the retail market, and let $\pi_{r i}$ be the Firm i's profit from its retail arm, so that

$$
\pi_{r i}=\left(p_{r i}-p_{w}\right) \beta_{i} X-c_{r i}\left(\beta_{i} X\right) .
$$

Firm i's total profit is then

$$
\pi_{i}=\pi_{w i}+\pi_{r i},
$$

and the relevant first-order condition for determining $\lambda_{i}$ is now

$$
\frac{\partial \pi_{i}}{\partial \lambda_{i}}=\frac{\partial \pi_{w i}}{\partial \lambda_{i}}-\frac{\partial p_{w}}{\partial \lambda_{i}} \beta_{i} X=0
$$




\section{Theorem 2:}

If all firms have the same market share in the retail market as they have in the wholesale market, there is a Nash equilibrium in which there is no over-reporting at all. In general, firms with a higher natural wholesale market share than retail will over-report while those with a lower market share will under-report, with the degree of mis-reporting being greater, the greater is the extent of mismatch.

\section{Proof:}

Consider the putative equilibrium in which $\lambda_{i}=1, \forall i$. In this case, $p_{i}=p_{w} \forall i$, $\omega_{i}=\theta_{i} \forall i$, and $Y\left(p_{i}\right)=Y\left(p_{w}\right)=X, \forall i$. Substituting these values into Equations (1) and (4) confirms the existence of the equilibrium. The general tendency for over-reporting when wholesale natural market share exceed the retail market share arises from the same increasing relationship between $\omega_{i}$ and $\lambda_{j}$ noted in the proof to Theorem 1 .

Theorem 2 is interesting for two reasons. First, it indicates an alternative route than Theorem 1 for achieving a perfectly competitive market. Theorem 1 indicates that in a nonvertically-integrated market, perfect competition requires atomistic firms, which is not compatible with the high fixed costs of electricity generation. Theorem 2, however, shows that vertical integration with market-share balance can achieve the same outcome.

Second, the theorem provides a way of interpreting pricing behaviour in a partially integrated market where there is a major player at either the generator or the retail level who is not present on the other side. Consider first the case with there is one generator without a retail arm while the remaining generators divide the retail market between them. In this case, Theorem 2 shows that each of the vertically integrated generators would under-report their inverse supply curves. To an observer, this behaviour might look like predatory pricing-that is, deliberately pricing below cost in order to induce exit of the non-integrated competitor and thus face lower competition in a later period. Our result, however, was obtained in a static one-shot game. That is, under-reporting inverse supply would be the profit maximising strategy in a single period without any consideration of future competition.

A similar situation applies when there is a major retailer without a generation arm. In this case, Theorem 2 implies that the generators would then have higher market shares in the wholesale market than in the retail market, and thus over-report their costs. Again, this is the Nash outcome in a static, one-shot game, but it could be construed as anti-competitive predatory behaviour of the generators trying to induce exit of the non-integrated retail firm. ${ }^{5}$

5 Allegations of such predatory conduct were made following the dry winter of 2001 and NGC's rapid exit from non-integrated retailing. They were considered by the then Market Surveillance Committee of the NZEM but not held to have involved either an abuse of market power or market manipulation. See NZEM (2001) or Evans and Meade (2005). 


\section{The Retail Market}

Now let's model the pricing behaviour of retail firms in some more detail. We assume that firms set prices and then commit to supplying whatever quantity is demanded at those prices. Each firm's demand and hence its profit is a function of its price and the prices of all other firms, so we write

$$
\pi_{i}=\pi_{i}\left(p_{r i}, \boldsymbol{p}_{r(-i)}\right),
$$

where $\boldsymbol{p}_{r(-i)}$ is the vector of prices of all retail firms other than firm $i$. In this price-setting model, firms set their price as a mark-up on marginal cost where the mark-up depends on the elasticity of the firm-specific demand functions. This elasticity depends on the degree of competition in the retail market and is independent of the degree of vertical integration. Where integration can matter is in determining marginal cost. To allow the notation to encompass different assumptions about the market structure, let $\phi_{i}$ be a parameter in firm i's profit function such that an increase in $\phi_{i}$ implies an increase in marginal cost for all output levels. Let $r_{i}\left(\boldsymbol{p}_{r(-i)}, \phi_{i}\right)$ be the best-response function for firm $i$. Rather than making assumptions about the demand structure underlying the profit functions and hence the bestresponse functions, we simply impose the following restrictions on $r_{i}\left(\boldsymbol{p}_{r(-i)}\right)$ :

\section{Assumption 1:}

a) $r_{i}\left(\boldsymbol{p}_{r(-i)}\right)$ is single-valued and continuous in $\boldsymbol{p}_{r(-i)}$ for all $i$

b) $\frac{\partial r_{i}\left(\boldsymbol{p}_{r(-i)}\right)}{\partial p_{r j}} \geq 0 \quad \forall j \neq i, \forall i$

c) $\exists \varepsilon<1$ s.t. $\sum_{j \neq i} \frac{\partial r_{i}\left(\boldsymbol{p}_{r(-i)}\right)}{\partial p_{r j}} \leq \varepsilon \quad \forall i$.

d) $\frac{\partial r_{i}\left(\boldsymbol{p}_{r(-i)}, \phi_{i}\right)}{\partial \phi_{i}}>0 \forall i$.

These assumptions encompass a large range of standard models, including perfect monopoly, and perfect competition.

\section{Theorem 3:}

a) If Assumption 1 holds, then there exists a unique retail-price Nash equilibrium, $\boldsymbol{p}_{r}^{*}$,

b) $\forall i, \quad \frac{\partial p_{r i}^{*}}{\partial \phi_{i}}>0, \quad \frac{\partial p_{r j}^{*}}{\partial \phi_{i}} \geq 0 \forall j \neq i$.

\section{Proof:}

Parts (a) - (c) of Assumption 1 guarantee that the best-response functions constitute a contraction mapping implying the existence of a unique equilibrium. (For a statement of this result, see Cachon and Netessine, (2003)). To see the second result, consider an equilibrium, 
$\boldsymbol{p}_{r}{ }^{*}$, with costs $\phi=\left(\phi_{1}, \phi_{2}, \cdots\right)$, and then consider alternative costs $\hat{\phi}=\left(\hat{\phi}_{1}, \hat{\phi}_{2}, \cdots\right)<\phi$. From Assumptions 1(b) and 1(d), we can see that the best-response functions must map $\times\left[0, p_{r j}{ }^{*}\right]$ onto itself. By the Brouwer fixed-point theorem, therefore, there must exist a fixedpoint that is not $\boldsymbol{p}_{r}{ }^{*}$, which, by part (a), must be the unique equilibrium.

The effect of the second part of Theorem 3 is that we only need to consider the effect on retail firms' marginal costs to analyse the effect of market structure on retail prices. Consider first a fully integrated market in which each retail firm was responsible for generating its own supply without there being a wholesale market.

\section{Theorem 4:}

Retail prices are higher in a non-vertically integrated market than in a fully integrated market without a wholesale market.

\section{Proof:}

In the case of a fully integrated market with no wholesale market, the marginal cost of each retail firm would be

$$
C_{i}^{\prime}+C_{r i}^{\prime} \text {. }
$$

In contrast, in a fully separated market, the marginal cost would be

$$
p_{w}+c_{r i}^{\prime} \text {. }
$$

From Theorem 1, however, we know that in a fully separated market,

$$
p_{w}>C^{\prime}{ }_{j} \forall j \text {. }
$$

The result then follows automatically.

Now consider a market where there is partial integration so that some retail firms have some presence as suppliers in the wholesale market. This will have two effects. First, the partial integration will affect the wholesale price through the mechanism described in Section 5. Second, the firm's marginal cost of selling an additional unit on the retail market also includes the negative of the change in wholesale profit at the margin. This occurs if the increase in the retailer's sales does not come fully at the expense of other retailers-that is, if its reducing its retail price induces more demand in part by having consumers purchase more in total rather than by substituting a fixed demand from one retailer to another. ${ }^{6}$ In this case, the firm's wholesale profit increases by its market share times the increase in total demand, $X$, times the difference between the wholesale price and generation marginal cost. This pushes

6 The secondary effect of changes in both total demand and market share on the equilibrium $\lambda_{i}$ and hence $p_{w}$ can be ignored because of the envelope condition. 
the firm's marginal cost closer to the pure technological cost of Equation (5). We can then consider the special case of perfect market share balance:

\section{Theorem 5:}

Retail prices in a vertically integrated market with market-share balance are the same as in a fully-integrated market with no wholesale market.

\section{Proof:}

From Theorem 2, we know that the wholesale price will just equal each firm's marginal cost of generation. The second-order effect on marginal cost if a retail price reduction induces an increase in total demand depends on a gap between $p_{w}$ and $c^{\prime}{ }_{j}$, which disappears in this case. The result follows automatically from this.

Theorems 4 and 5 have implications for competition policy in the electricity market. The key result is that any monopoly power that exists in the retail market exists independently of the market structure. Changes in the structure can only affect retail prices through effects on the marginal cost that is marked up. The best outcome that can be achieved for retail prices through competition policy at the wholesale level is to try and induce market share balance between the two markets. So, for instance, if the retail market were characterised by high monopoly power with only one or two firms competing for customers, with a similar concentration in the wholesale market, it would be a mistake (in this model) to try and induce greater competition in the wholesale market by breaking up generation companies into smaller units.

\section{Discussion}

Our model's prediction that vertically integrated generators will over-report their inverse supply curves when their wholesale market share exceeds their retail market share resembles the findings of others that vertically integrated generators that are net sellers have an incentive to exercise market power (Mansur (2003), Kuhn and Machado (2004)). Indeed, our prediction concurs with Kuhn and Machado's, that entry by non-integrated retailers could increase spot wholesale prices since it would cause generators to become net sellers. Superficially this suggests that the acquisition of retail customer bases by generators after April 1999, and the sale of non-integrated NGC's retail customer base to generators in 2001, should have been beneficial for wholesale pricing in New Zealand.

Newbery (2002) extends this analysis, noting that competition among non-vertically integrated retailers also increases wholesale price risks to generators, with adverse consequences for investment. This is because such retailers prefer short-term over long-term contracts to mitigate their risk of falling wholesale prices. As Newbery puts it (p. 2): “The natural response to this increased risk is for incumbents to vertically and horizontally integrate to better manage risk, deter entry, manage the capacity margin, and hence restore prices to profitable levels." Chao et al. (2005) similarly observe the mutuality of interest between generators and retailers to mitigate systemic risks in electricity markets. However, Newbery 
(2002) cautions against such integration because of adverse effects on entry, instead preferring the maintenance of retail customer franchises under yardstick competition (which Finon (2006) also argues to be an effective alternative to integration).

\section{Conclusion}

Our model suggests that vertical integration between generation and retailing in electricity markets should not be presumed to worsen generator market power in either wholesale or retail markets. On the contrary, it predicts that the incentive to exercise wholesale market power always exists when generators and retailers are vertically separated. Conversely, where the incentive to exercise market power arises under vertical integration, our work suggests that it is the mismatch between wholesale and retail market shares - not absolute market share itself - that is the cause. Even in this case, however, the prediction holds true for integrated generators that are net sellers. For net buyers the reverse is true, with an incentive to under-report wholesale prices (although our model's static setting means this result cannot be taken to imply predatory pricing).

Since retail market power involves firms marking up their retailing marginal costs, this suggests that minimising such retail market power as well as wholesale prices are both important in welfare terms. However, with vertical integration we find that inter-market balance is the relevant consideration when minimising wholesale prices, whereas under vertical separation wholesale market competitiveness remains a valid concern. Because of the impossibility of perfectly competitive wholesale markets given current generation technologies, this implies that the wholesale price component of retail prices can only feasibly be minimised by the pursuit of balanced vertical integration, even when there is only a limited number of generators. By contrast, with vertical separation wholesale prices will, realistically, always be overstated.

Obvious extensions that would enhance the usefulness of these findings include allowing for spatial considerations such as network effects and wholesale market "regionalisation" due to transmission constraints. They would also include dynamic considerations such as the impact of vertical integration on the management of wholesale market price risks and investment incentives. These extensions are left for future research.

In policy terms our work suggests that caution be exercised when considering whether vertical separation should be imposed on generators, particularly where adequate contract markets cannot be demonstrated to provide an adequate alternative. It also suggests that care should be exercised when assessing whether any particular generator is in a position to exercise market power in either wholesale or retail markets, since the extent of its vertical integration into retailing will be a relevant consideration. Aside from addressing retail market power directly, electricity reformers and competition authorities would do best by allowing balanced vertical integration to evolve. Based on our analysis, with balanced vertical integration in place attention would be better paid to any market power in electricity retailing. 


\section{References}

Borenstein, S., 2002, “The Trouble with Electricity Markets: Understanding California’s Restructuring Disaster”, Journal of Economic Perspectives, Winter, 191-211.

Borenstein, S., Bushnell, J. and F. Wolak, 2002, "Measuring Market Inefficiencies in California’s Restructured Wholesale Electricity Market”, American Economic Review, 92(5), 1376-1405.

Buehler S., A. Schmutzler, A. and M.-A. Benz, 2003, "Infrastructure Quality in Deregulated Industries: Is there an Underinvestment Problem?”, CEPR Discussion Paper No. 3836, March.

Bushnell, J., Mansur, E. and C. Saravia, 2004, "Market Structure and Competition: A Cross-Market Analysis of U.S. Electricity Deregulation”, CSEM Working Paper 126.

Bushnell, J. and C. Saravia, 2002, “An Empirical Assessment of the Competitiveness of the New England Electricity Market”, CSEM Working Paper 101.

Cachon, G. P. and S. Netessine, 2003, “Game Theory in Supply Chain Analysis”, mimeo available at http://www2.isye.gatech.edu/ pinar/teaching/isye6230-spring2004/GT-inSC-analysis-cachon-netessine2003.pdf.

Came, S. and M. Dupuy, 2005, "Pricing in Wholesale Electricity Markets", Policy Perspectives Paper 05/03, New Zealand Treasury, June.

Chao, H.-P., Oren, S. and R. Wilson, Restructured Electricity Markets: Reevaluation of Vertical Integration and Unbundling, July.

Cooper, J., Froeb, L., O’Brien, D. and G. Vita, Vertical Antitrust as a Problem of Inference, Federal Trade Commission, February.

Dupuy, M., 2006, "Electricity Generation: Competition, Market Power and Investment”, Policy Perspectives Paper 06/04, New Zealand Treasury, July.

Evans, L. and R. Meade, 2005, Alternating Currents or Counter-Revolution: Contemporary Electricity Reform in New Zealand, Victoria University Press.

Finon, D., 2006, "Incentives to Invest in Liberalised Electricity Industries in the North and the South. Differences in the Need for Suitable Institutional Arrangements”, Energy Policy, 34, 601-618.

Joskow, P. and E. Kahn, 2002, "A Quantitative Analysis of Pricing Behaviour in California’s Wholesale Electricity Market during Summer 2000”, Energy Journal, 23(4), 135.

Kuhn, K.-U. and M. P. Machado, 2004, "Bilateral Market Power and Vertical Integration in the Spanish Electricity Spot Market, CEMFI Working Paper No. 0414, September.

Mansur, E., 2003, "Vertical Integration in Restructured Electricity Markets: Measuring Market Efficiency and Firm Conduct”, Working Paper \#32, Yale School of Management, October. 
Mansur, E., 2004, Upstream Competition and Vertical Integration in Electricity Markets, Yale University.

Meade, R., 2005a, "Electricity Investment and Security of Supply in Liberalized Electricity Systems”, in W. Mielczarski (ed.), Development of Electricity Markets.

Meade, R., 2005b, Intervention in Electricity Investment: Required, or SelfPerpetuating?, Seminar, New Zealand Institute for the Study of Competition and Regulation, Victoria University of Wellington, December.

Ministry of Economic Development, 2006, Energy Data File, September.

Newbery, D., 2002, Mitigating Market Power in Electricity Networks, Cambridge University, May.

New Zealand Electricity Market (NZEM), 2001, Claimed "Undesirable Situation" Arising From High Spot Prices in May/June 2001, Memorandum from the Market Surveillance Committee, 17 July.

Riechmann, C., 2000, "Strategic Pricing of Grid Access Under Partial Price-Caps Electricity Distribution in England and Wales”, Energy Economics, 22, 187-207.

Wilson, R., 2002, “Architecture of Power Markets”, Econometrica, 70(4), July, 12991340 . 